\title{
Pulmonary Rehabilitation in COPD According to Global Initiative for Chronic Obstructive Lung Disease Categories
}

\author{
Sara Alfarroba MSc MD, Fátima Rodrigues PhD MD, Ana Luísa Papoila PhD, \\ Ana Filipe Santos PT, and Luísa Morais PT
}

\begin{abstract}
BACKGROUND: Pulmonary rehabilitation (PR) programs are a mainstay for treatment in COPD. Lung function impairment alone does not predict beneficial effects of PR. The new COPD categories take into account assessment of symptoms, such as dyspnea and exacerbations, which may be important indications for PR. This study evaluates the effect of PR on exercise capacity, symptoms, and health status in different COPD categories. METHODS: Subjects with COPD referred for PR were classified into COPD categories A, B, C, and D. Exercise capacity (6-min walk distance [6MWD] and constant work rate at $80 \%$ of peak work rate), symptoms (Mahler's index), and health status (St George Respiratory Questionnaire) were compared before and after PR programs for each COPD category. Changes were analyzed using generalized estimating equations and logistic regression models. RESULTS: One hundred sixty-seven subjects were included (COPD categories A [16\%], B [12\%], C [31\%], and D [41\%]). Groups were homogeneous in age, body mass index, smoking pack-years, and comorbidities. Significant improvements in all outcomes were found after adjusting for COPD categories, age, sex, body mass index, and COPD-specific comorbidity index. All COPD categories improved exercise capacity (6MWD and constant work rate). Categories A and $\mathrm{C}$ had more pronounced improvements in 6MWD than categories $\mathrm{B}$ and D. Symptoms (Mahler's index) also improved significantly in categories $A$ and $C$, whereas change was not significant in categories B and D. Global health status (St George Respiratory Questionnaire) improved significantly in all COPD categories. Despite these differences, the odds of achieving a minimum clinically important difference in each outcome were similar and without statistical significance for the A, B, and $C$ categories when compared with D. CONCLUSIONS: This study demonstrates that patients in all COPD categories may improve exercise capacity, symptoms, and health status with PR programs, and COPD categories alone may not be sufficient to discriminate which patients may benefit most from them. Key words: pulmonary rehabilitation; COPD; COPD categories; quality of life; 6-min walking distance; constant work rate; St George Respiratory Questionnaire; Mahler's index. [Respir Care 2016;61(10):1331-1340. (c) 2016 Daedalus Enterprises]
\end{abstract}

\section{Introduction}

COPD is a debilitating disease commonly causing varying degrees of dyspnea, deconditioning, and difficulties in

\footnotetext{
Dr Alfarroba, Dr Rodrigues, Ms Santos, and Ms Morais are affiliated with the Serviço de Pneumologia, Hospital Pulido Valente, Centro Hospitalar Lisboa Norte, Lisbon, Portugal. Drs Rodrigues and Papoila are affiliated with the NOVA Medical School/Faculdade de Ciências Médicas, Universidade Nova de Lisboa, Lisbon, Portugal. Dr Papoila is also affiliated with the Centro de Estatística e Aplicações da Universidade de Lisboa, Lisbon, Portugal.
}

The authors have disclosed no conflicts of interest. daily activities. ${ }^{1,2}$ Although primarily a respiratory condition with increased work of breathing, the systemic effects of COPD result in loss of skeletal muscle mass and function, contributing to muscle weakness. Skeletal muscle atrophy is a clear negative prognostic factor, ${ }^{3}$ and loss of quadriceps strength has been shown to predict mortality in

Correspondence: Sara Alfarroba MSc MD, Serviço de Pneumologia, Hospital Pulido Valente, Centro Hospitalar Lisboa Norte. Alameda das Linhas de Torres, $n^{\circ} 117$ 1769-001 Lisboa, Portugal.E-mail: sara.alfa@ netcabo.pt.

DOI: $10.4187 /$ respcare. 04414 
COPD. ${ }^{4}$ Individuals with COPD also have multiple risk factors for cardiovascular disease, including smoking, physical inactivity, and metabolic disorders, ${ }^{5}$ and psychological well-being is also affected by physical and social impairments.

Pulmonary rehabilitation (PR) programs are considered to be a mainstay of treatment in $\mathrm{COPD}^{6}$ and have been clearly demonstrated to reduce dyspnea, increase exercise capacity, and improve quality of life. ${ }^{7-9}$ The American Thoracic and European Respiratory Societies currently recommend PR programs to be comprehensive interventions with patient-tailored therapies that include exercise training, self-management education, and behavior change, designed to improve physical and psychological condition. ${ }^{2}$ Although PR programs are costly and time-consuming with interventions that include comprehensive patient screening and treatment by a specialized team, studies have demonstrated their cost-effectiveness in moderate to severe COPD. ${ }^{10}$ It is important to quantify the success of such programs and determine which participants benefit most from them.

PR programs have traditionally enrolled individuals with severe COPD, persistent symptoms, or dyspnea as measured by the Modified Medical Research Council breathlessness scale (mMRC) $\geq 2$ (or MRC $\geq 3$ ), according to the British Thoracic Society and American Thoracic Society/European Respiratory Society guidelines. ${ }^{2,11}$ However, this paradigm is changing as increasing data suggest that patients with less severe disease and fewer symptoms also improve significantly across several outcomes. ${ }^{2}$ Individuals with mMRC scores 1 and 2 have been shown to improve exercise performance and health status as much as individuals with higher $\mathrm{mMRC}$ scores. ${ }^{12-15} \mathrm{PR}$ programs for mild COPD have also been successful with similar improvements in exercise capacity, quality of life scores, and symptoms as in programs for more severe COPD. ${ }^{16,17}$

Evidence has shown that degree of lung impairment alone (assessed by spirometry) is poorly correlated with exercise capacity ${ }^{12,18}$ and health status. ${ }^{19}$ Similarly, lung function alone does not predict beneficial effects of PR programs; nor can it be used as a sensitive outcome of intervention success. ${ }^{2}$

According to current guidelines, ${ }^{1}$ COPD is classified into categories $\mathrm{A}, \mathrm{B}, \mathrm{C}$, and $\mathrm{D}$, which take into account clinical assessment of symptoms and exacerbations, as well as lung function. Patients with COPD with $\mathrm{FEV}_{1}>50 \%$, $<2$ respiratory exacerbations in the previous year, and no hospital stays for respiratory exacerbations are classified as COPD categories A and B. Patients with either FEV 1 $<50 \%$ or $\geq 2$ respiratory exacerbations or one hospital stay due to a respiratory exacerbation in the previous year are classified as COPD categories $\mathrm{C}$ and $\mathrm{D}$. The presence of symptoms, as measured by an mMRC score $\geq 2$ or a COPD Assessment Test score $\geq 10$, indicates categories B

\section{QUICK LOOK}

\section{Current knowledge}

Pulmonary rehabilitation (PR) programs are considered to be a mainstay of treatment in COPD. PR programs traditionally enroll individuals with severe COPD, persistent symptoms or dyspnea. However, increasing data suggest that patients with less severe disease and symptoms also improve significantly with PR. PR programs for mild COPD have also been successful with similar improvements in exercise capacity, quality of life scores and symptoms as in programs for more severe COPD.

\section{What this paper contributes to our knowledge}

All COPD categories (A,B,C and D) may benefit from $\mathrm{PR}$, as demonstrated in this hospital-based PR unit, with both statistically and clinically meaningful improvements in exercise performance and health-related quality-of-life. Improvements in 6-min walk distance and Mahler's baseline and transitional dyspnea index were greater in COPD categories A and C than category D. Constant work rate and Saint George Respiratory Questionnaire had similar improvements in all categories. The odds of achieving minimum clinical important difference in all outcomes was similar across all COPD categories.

or D. This classification reflects functional impairments that may be important indicators for rehabilitation programs and may support patient referral to PR units. The aim of this study was to evaluate the effects of PR on exercise capacity, symptoms, and health status in subjects of different COPD categories.

\section{Methods}

\section{Study Design and Participants}

This was a prospective cohort study. Individuals with COPD referred to the out-patient PR unit of Pulido Valente Hospital were examined by a pulmonologist, and those meeting the inclusion criteria were recruited consecutively from May 2010 to May 2015 for a full PR program.

Included subjects were willing and able to participate in this hospital-based program and gave written informed consent, before baseline measurements, for the collection of personal data for research purposes. Subjects had post-bronchodilator results on most recent spirometry of $\mathrm{FEV}_{1} / \mathrm{FVC}<0.7$ and had a history of smoking habits or clinical equivalent. All individuals had their therapy opti- 
mized and were clinically stable, defined as no change in dyspnea, cough, or sputum beyond everyday variability or requirement of antibiotic therapy in the preceding month. Patients were excluded from the study if they had unstable cardiac disease, severe orthopedic disease, or any sensory or cognitive impairment. The hospital's ethics committee and administration board approved the trial (institutional review board approval DIRCLIN-20141222-479/2014), and all data were processed anonymously according to the institution's privacy policy.

\section{The Out-Patient Pulmonary Rehabilitation Program}

The PR program was multidisciplinary, including pulmonologists, dedicated physiotherapists and nurses, nutritionists, and psychologists. Subjects attended the PR unit 3 times/week. After an initial phase for education and adaptation to exercise equipment, individuals were assessed for a peak work rate on an initial incremental exercise test on bicycle ergometer or treadmill. PR programs had an 8-12week duration. Individually prescribed training programs included (1) aerobic exercise training on a treadmill or bicycle at a target intensity of $60-80 \%$ of peak work rate; (2) peripheral muscle exercises by circuit training on various strength equipment for abdominal and upper and lower limb exercises and weight lifting; and (3) breathing control and sputum clearance techniques, according to the subjects' needs. These activities were supervised by physiotherapists.

Subjects already using home ambulatory oxygen supplementation were provided with oxygen for exercise training purposes. Subjects who did not use ambulatory oxygen were not provided with supplemental oxygen unless exercise itself resulted in desaturation with unacceptable degrees of dyspnea or fatigue, objectively reversible with oxygen supply to achieve $90 \%$ of $\mathrm{S}_{\mathrm{pO}_{2}}$. Subjects were encouraged to apply a home-exercise routine as a way to enhance activity levels and improve activity of daily living efficacy. Throughout the PR program, subjects were engaged in individualized or group self-management sessions provided by a multidisciplinary rehabilitation team. These sessions included education on the correct use of respiratory medication and the importance of regular physical activity and smoking cessation as well as identification of symptoms and signs of exacerbations. When required, psychologist and nutritionist counseling and social support were provided. During the PR program, subjects were encouraged to continue the various strategies they had acquired in their home setting environment.

\section{Data Collection}

Demographic information and the results of spirometry performed on subjects entering the program were collected.
The mMRC uses a simple grading system to score a patient's dyspnea with a 5-point scale, from 0 to 4 . It was used as a discriminative tool to characterize the study sample. ${ }^{20,21}$ The number of exacerbations in the year before the PR program was obtained from medical records based on the number of visits to the emergency department and hospital stays. Subjects were classified into Global Initiative for Chronic Obstructive Lung Disease (GOLD) COPD categories A, B, C, and D, ${ }^{1}$ according to the mMRC breathlessness scale, post-bronchodilator $\mathrm{FEV}_{1}$, and number of exacerbations in the previous year.

The BODE index (body mass index, air flow obstruction, dyspnea, and exercise capacity) was calculated at baseline using values for $\mathrm{kg} / \mathrm{m}^{2}$, percent-of-predicted $\mathrm{FEV}_{1}$, mMRC, and 6-min walk distance in meters, respectively, ${ }^{22}$ and is a tool for predicting life expectancy of patients with COPD.

Comorbidities were recorded and used to assess the COPD-specific comorbidity index (COTE), which includes the comorbidities with the most robust association with increased death (cancers, pulmonary fibrosis, atrial fibrillation/flutter, congestive heart failure, coronary artery disease, gastric/duodenal ulcers, liver cirrhosis, diabetes with neuropathy, and anxiety). ${ }^{23}$ The presence of respiratory failure was also recorded.

Regarding the PR program, adherence was assessed by determining the number of sessions that were attended by each subject. A minimum of $70 \%$ attendance was required for fulfilling the program. Those who failed to adhere were considered dropouts. The success of the PR program was evaluated by assessing the improvement in 4 main outcomes measured at baseline and at the end of the PR program. Exercise capacity was measured through the 6-min walk distance (6MWD), according to American Thoracic Society guidelines, ${ }^{24}$ on a $30-\mathrm{m}$ walking course, where subjects were instructed to walk as far as possible for 6 min, and the constant work rate endurance test, measured in minutes on a bicycle ergometer or treadmill at $80 \%$ of the peak work rate. ${ }^{25,26}$ Minimum clinically important difference was defined at $35 \mathrm{~m}$ for the $6 \mathrm{MWD}$, according to distribution- and anchor-based methods, ${ }^{27,28}$ and $85 \mathrm{~s}$ for the constant work rate, according to an anchor-based method with a 5-point Likert scale. ${ }^{29}$ Symptom control was assessed by Mahler's baseline and transitional dyspnea index, ${ }^{30}$ a scale of 5 grades, scored $0-4$, for each of the categories: functional impairment, magnitude of task, and magnitude of effort. Scores ranged from -9 to +9 , with positive scores representing improvement in dyspnea, and the minimum clinically important difference was defined as a change of at least 1 point. Health status was assessed by the St George Respiratory Questionnaire, a 76-weighted-item questionnaire, in which results are expressed for symptoms, activity, and impacts on daily life. An integrated total score reflects health impairment, where 
zero indicates no impairment and 100 represents maximum impairment. A variation of at least 4 points in global score was considered to reflect the minimum clinically important difference. ${ }^{31,32}$

\section{Statistical Analysis}

An exploratory analysis was carried out for all variables. Categorical data are presented as frequencies (percentages), and continuous variables are presented as mean and SD or median and interquartile range, as appropriate. Baseline characteristics between COPD categories were compared using a chi-square test or Fisher exact test and Kruskal-Wallis test, as required.

To assess intervention crude effect on 6MWD, constant work rate, baseline and transitional dyspnea index, and $\mathrm{St}$ George Respiratory Questionnaire values in each COPD category, error bar plots expressing the means of outcome differences between the end and the beginning of the intervention (variation) and corresponding 95\% CIs were constructed. Additionally, to obtain the statistical significance of these intervention effects, tests for paired samples were applied. No multiple-testing correction methods were used due to the exploratory nature of this study.

To assess the intervention effect, adjusted by other covariates and potential confounders (age, sex, body mass index, and COTE), generalized estimating equations with an exchangeable correlation structure were used to take into account the autocorrelation between longitudinal measures. Regarding the proportion of subjects who attained a minimum clinically important difference in $6 \mathrm{MWD}$, constant work rate, baseline and transitional dyspnea index, and St George Respiratory Questionnaire outcomes, the odds ratios of each COPD category (considering category $\mathrm{D}$ as reference) were obtained by logistic regression models as well as corresponding 95\% CIs.

The level of significance $\alpha=.05$ was considered. Data analysis was performed using the software SPSS 22.0 for Windows, release 22.0.1.2013 (SPSS, Chicago, Illinois) and Stata, release 13 (StataCorp, College Station, Texas).

\section{Results}

One hundred sixty-seven subjects were included in this study, of whom $16 \%$ were classified in COPD category A, $12 \%$ in COPD category B, $31 \%$ in COPD category C, and $41 \%$ in COPD category D (Table 1). Most individuals (94\%) had a past or current smoking status. There were no significant differences in age, body mass index, and smoking pack-years between groups. Male sex was more prevalent in COPD categories $\mathrm{C}$ and $\mathrm{D}$ than in COPD categories $\mathrm{A}$ and $\mathrm{B}(P=.001)$. Spirometry results differed between groups $(P \leq .001)$.
BODE was significantly different between categories, with higher scores in category $\mathrm{D}(P<.001)$. Most subjects (91\%) had cardiovascular comorbidities, of which arterial hypertension was the most frequently recorded (49\%), followed by ischemic heart disease (13\%), heart failure (9.5\%), arrhythmias (9.5\%), and cor pulmonale (9\%). 19\% had architectural distortion of the lung from past pulmonary tuberculosis, and $28 \%$ had some degree of bronchiectasis, although these were not patients' primary lung disease. Alpha-1 antitrypsin deficiency was found in $6.6 \%$ of subjects. Obstructive sleep apnea-hypopnea syndrome was found in $14 \%$ subjects. Diabetes mellitus was found in $13 \%$, obesity in $12.6 \%$, and hypercholesterolemia in $17 \%$ of subjects. Orthopedic disorders were present in $16 \%$. Depression or anxiety was reported in $7 \%$ of individuals, as were thyroid disorders. Only the occurrence of hypercholesterolemia was found to be different between categories, being more prevalent in categories $\mathrm{A}, \mathrm{B}$, and $\mathrm{C}$ $(P=.030)$. The COTE index was not significantly different between categories $(P=.47)$. Hypoxemic respiratory failure, found in a total of $39.5 \%$ of subjects, was equally present across all categories $(P=.23)$. However, hypercapnic respiratory failure, found in $25.1 \%$ of subjects, was significantly more frequent in category $\mathrm{D}$ and less frequent in category A $(P=.001)$ (see Table 1$)$.

Individuals in COPD category A were found to be referred to the rehabilitation unit due to at least one of the following: hypoxemic respiratory failure or desaturation on exertion (74\%), persistent productive cough (15\%), obesity (15\%), malnutrition (7\%), and, in one case, hypercapnic respiratory failure.

A total of 132 subjects completed the PR program at a mean $73 \%(S D=11.5)$ of peak work rate. Dropouts were due to non-adherence and unwillingness to complete the program (9 cases), learning difficulties or psychological impairment to progress in the program ( 6 cases), COPD exacerbations that forced interruption ( 5 cases), familial or economic issues (3 cases), skeletal muscle impairment (3 cases), diagnosis of other non-related diseases during the time undertaking PR that forced interruption ( 2 cases), and cardiovascular complications including tachyarrhythmia (4 cases), one deep vein thrombosis, and one arterial ischemia of the lower limbs. One death was recorded during the study period, which occurred during night sleep in a subject with coronary artery disease and a past history of myocardial infarction. Death was attributed to myocardial infarction. The percentage of dropouts was not significantly different between COPD categories $(P=.08)$. When comparing dropouts with subjects who fulfilled the PR program, no statistical differences were found in age $(P=.33)$, sex $(P=.46)$, body mass index $(P=.055)$, smoking habits $(P=.62)$, mMRC score $(P=.18)$, and air flow limitation as percent-of-predicted $\mathrm{FEV}_{1}(P=.052)$. 
Table 1. Characteristics of Study Participants at Baseline

\begin{tabular}{|c|c|c|c|c|c|c|}
\hline Characteristics & $\begin{array}{c}\text { Total } \\
(N=167)\end{array}$ & $\begin{array}{l}\text { COPD A } \\
(n=27)\end{array}$ & $\begin{array}{l}\text { COPD B } \\
(n=20)\end{array}$ & $\begin{array}{l}\text { COPD C } \\
(n=52) \\
\end{array}$ & $\begin{array}{l}\text { COPD D } \\
(n=68)\end{array}$ & $P$ \\
\hline Male sex, $n(\%)$ & $137(82.0)$ & $18(66.6)$ & $13(65.0)$ & $50(96.2)$ & $56(82.4)$ & $.001 *$ \\
\hline Age, mean \pm SD y & $65.2 \pm 9.5$ & $66.9 \pm 10.9$ & $64.1 \pm 11.9$ & $65.7 \pm 8.5$ & $64.5 \pm 9.0$ & $.58 \dagger$ \\
\hline $\mathrm{BMI}$, mean $\pm \mathrm{SD} \mathrm{kg} / \mathrm{m}^{2}$ & $26.2 \pm 4.8$ & $26.7 \pm 4.8$ & $28.1 \pm 5.3$ & $25.7 \pm 4.1$ & $25.7 \pm 4.9$ & $.26 \dagger$ \\
\hline Smoking, median (IQR) pack-years & $50(40-73)$ & $50(44-75)$ & $50(39-90)$ & $51(38-70)$ & $54(40-74)$ & $.93 \dagger$ \\
\hline BODE, median (IQR) & $3(2-5)$ & $1(0-2)$ & $2(1-3)$ & $3(2-4)$ & $5(4-6)$ & $<.001 \dagger$ \\
\hline COTE, median (IQR) & 0.0 & $0.0(0.0-2.0)$ & $0.0(0.0-1.0)$ & $0.0(0.0-1.0)$ & $1(0.0-2.0)$ & $.47 \dagger$ \\
\hline Hypoxemic RF, $n(\%)$ & $66(39.5)$ & $13(48.1)$ & $10(50.0)$ & $15(28.8)$ & $28(41.2)$ & $.23 \ddagger$ \\
\hline Hypercapnic RF, $n(\%)$ & $42(25.1)$ & $1(3.7)$ & $2(10.0)$ & $12(23.1)$ & $27(39.7)$ & $.001 \%$ \\
\hline FVC, median (IQR) L & $2.7(2.3-3.5)$ & $3.3(2.6-3.9)$ & $2.9(2.7-3.4)$ & $2.9(2.3-3.5)$ & $2.4(2.1-3.0)$ & $.001 \dagger$ \\
\hline FVC, median (IQR) \% predicted & $81.0(69-102)$ & $94.0(84-107)$ & $96.0(85-108)$ & $81.0(64-93)$ & $74.0(62-85)$ & $<.001 \dagger$ \\
\hline $\mathrm{FEV}_{1}$, median (IQR) L & $1.1(0.9-1.5)$ & $1.7(1.3-2.1)$ & $1.5(1.2-1.4)$ & $1.1(0.9-1.4)$ & $0.9(0.7-1.82)$ & $<.001 \dagger$ \\
\hline $\mathrm{FEV}_{1}$, median (IQR) $\%$ predicted & $42.0(33-57)$ & $65.0(55-74.5)$ & $62.0(51-82)$ & $40.5(32-48)$ & $34.0(30-41)$ & $<.001 \dagger$ \\
\hline $\mathrm{FEV}_{1} / \mathrm{FVC}$, median (IQR) $\%$ predicted & $43.0(34-53)$ & $52.0(49-59)$ & $51.0(44-61)$ & $42.0(34-49)$ & $36.0(32-47)$ & $<.001 \dagger$ \\
\hline 6MWD, median (IQR) m & $330(280-442.5)$ & $422(328-490)$ & $355(318-475)$ & $360(304-453)$ & $290(245-374)$ & $<.001 \dagger$ \\
\hline CWR, median (IQR) min & $5(3-12)$ & $5(3-13)$ & $7(3-15)$ & $5(3-15)$ & $5(3-10)$ & $.89 \dagger$ \\
\hline Mahler BDI, median (IQR) & $7(6-9)$ & $8(6.8-10)$ & $8.0(6-9)$ & $8(6-10)$ & $6(5-8)$ & $.001 \dagger$ \\
\hline $\mathrm{SGRQ}$, mean $\pm \mathrm{SD}$ & $45.6 \pm 17.3$ & $38.1 \pm 14.7$ & $46.2 \pm 16.1$ & $37.3 \pm 13.4$ & $56.5 \pm 16.2$ & $<.001 \dagger$ \\
\hline Dropouts, $n(\%)$ & $35(21.0)$ & $1(3.7)$ & $4(20.0)$ & $13(25.0)$ & $17(25.0)$ & $.075^{*}$ \\
\hline $\begin{array}{l}\text { * Fisher exact test. } \\
\dagger \text { Kruskal-Wallis test. } \\
\text { † Chi-square test. } \\
\text { BMI = body mass index } \\
\text { IQR }=\text { interquartile range } \\
\text { BODE = body mass index, air-flow obstruction, dys } \\
\text { COTE = COPD-specific comorbidity test } \\
\mathrm{RF}=\text { respiratory failure } \\
6 \mathrm{MWD}=6 \text {-min walking distance } \\
\mathrm{CWR}=\text { constant work rate } \\
\text { BDI = baseline dyspnea index } \\
\text { SGRQ = St George Respiratory Questionnaire }\end{array}$ & a, and exercise capacity $i$ & & & & & \\
\hline
\end{tabular}

\section{Outcomes}

Baseline measurements for the median 6MWD were significantly different between categories A, B, C, and D $(P<.001)$, where COPD category A subjects fared better and COPD category D subjects fared significantly worse. Constant work rate was found to be similar between all COPD categories at baseline $(P=.89)$. Mahler's baseline dyspnea index evidenced a lower score in category D $(P=.001)$. Similarly, values for quality of life measured with the St George Respiratory Questionnaire were found to be significantly worse at baseline in COPD categories B and D $(P<.001)$, as shown in Table 1 .

As a whole, subjects with COPD had a significant improvement in all end points after PR (Table 2). In fact, considering the intervention effect as the mean difference between post- and pre-PR outcome values, clinically and statistically significant effects were found for 6MWD $(51.33 \mathrm{~m})$, constant work rate $(8.47 \mathrm{~min})$, dyspnea index (1.04), and St George Respiratory Questionnaire (-8.08), independent of COPD category, age, sex, body mass index, and COTE (see Table 2). Significant differences in most outcomes were also found within each COPD category (Fig. 1).

Regarding 6MWD, values improved significantly in all COPD categories (see Fig. 1). Generalized estimating equation results showed significant differences in intervention effect in 6MWD between categories, with categories A and $\mathrm{C}$ having higher values after PR programs when compared with category D (see Table 2). We also found that the variables age and COTE index had a negative impact in 6MWD values (see Table 2).

The proportion of subjects with a $\geq 35-\mathrm{m}$ (minimum clinically important difference) increase in 6MWD was $56.1 \%$. Logistic regression analysis showed no difference in the odds of achieving a minimum clinically important difference for the $\mathrm{A}, \mathrm{B}$, and $\mathrm{C}$ COPD categories, when compared with the D category (Table 3 ).

Exercise capacity, as measured by the constant work rate endurance test, evidenced significant improvements after the PR program. There was a highly significant improvement in constant work rate in all COPD categories (see Fig. 1). The A, B, and C categories showed higher values when compared with $\mathrm{D}$, although without statistical 
Table 2. Improvement in Outcomes by Generalized Estimating Equations

\begin{tabular}{|c|c|c|c|}
\hline Outcomes & $\begin{array}{c}\text { Regression } \\
\text { Coefficient } \\
\text { Estimate }\end{array}$ & $95 \% \mathrm{CI}$ & $P$ \\
\hline \multicolumn{4}{|l|}{ 6MWD, m } \\
\hline Intervention effect & 51.33 & $40.98-61.68$ & $<.001$ \\
\hline COPD A & 127.34 & $85.63-169.06$ & $<.001$ \\
\hline COPD B & 51.19 & $3.32-99.05$ & .036 \\
\hline COPD C & 70.40 & $36.16-99.05$ & $<.001$ \\
\hline Age & -1.72 & -3.24 to -0.19 & .03 \\
\hline COTE & -13.18 & -21.34 to -5.02 & .002 \\
\hline \multicolumn{4}{|l|}{ CWR, min } \\
\hline Intervention effect & 8.47 & $6.60-10.34$ & $<.001$ \\
\hline COPD A & 1.70 & -4.04 to 7.44 & .56 \\
\hline COPD B & 2.21 & -4.65 to 9.08 & .53 \\
\hline COPD C & 2.49 & -2.46 to 7.44 & .32 \\
\hline Age & -0.28 & -.48 to -0.07 & .009 \\
\hline \multicolumn{4}{|l|}{ BDI/TDI } \\
\hline Intervention effect & 1.04 & $0.39-1.69$ & .002 \\
\hline COPD A & 3.44 & $2.07-4.82$ & $<.001$ \\
\hline COPD B & 1.87 & $0.22-3.52$ & .03 \\
\hline COPD C & 2.81 & $1.58-4.04$ & $<.001$ \\
\hline \multicolumn{4}{|l|}{ SGRQ } \\
\hline Intervention effect & -8.08 & -10.60 to -5.55 & $<.001$ \\
\hline COPD A & -19.11 & -25.94 to -12.28 & $<.001$ \\
\hline COPD B & -12.06 & -20.54 to -3.58 & .005 \\
\hline COPD C & -19.27 & -25.17 to -13.37 & $<.001$ \\
\hline
\end{tabular}

See the text for explanation of equations.

$6 \mathrm{MWD}=6$-min walking distance

COTE $=$ COPD-specific comorbidity test

$\mathrm{CWR}=$ constant work rate

$\mathrm{BDI} / \mathrm{TDI}=$ baseline and transitional dyspnea index

SGRQ $=$ St George Respiratory Questionnaire

significance (see Table 2). Once again, age was found to have a negative impact on constant work rate values.

$56.9 \%$ of subjects achieved a minimum clinically important difference of $85 \mathrm{~s}$ in constant work rate after PR. Logistic regression analysis showed that the odds of attaining a minimum clinically important difference were higher for the A, B, and C categories, when compared with D, although without statistical significance (see Table 3).

Regarding symptom control, as measured by Mahler's index, we found that COPD categories A and C improved significantly with the PR, but there was no significant change in the baseline and transitional dyspnea index in COPD categories B and D (see Fig. 1). Generalized estimating equation results also showed that Mahler's index values were significantly different in categories $\mathrm{A}, \mathrm{B}$, and $\mathrm{C}$ when compared with category D (see Table 2).

$54 \%$ of subjects had at least a 1-point improvement in Mahler's index. Compared with category D, the odds of attaining this improvement were higher in the $\mathrm{A}$ and $\mathrm{C}$ categories, although with no statistical significance (see Table 3).

Finally, all COPD categories had a significant improvement in St George Respiratory Questionnaire scores with the PR program (see Fig. 1). There were significant differences in mean values in this outcome in categories $A$, $\mathrm{B}$, and $\mathrm{C}$ when compared with category $\mathrm{D}$ by generalized estimating equations (see Table 2). $63.8 \%$ of subjects achieved minimum clinically important difference with a decrease of $\geq 4$ points in the St George Respiratory Questionnaire, and the odds of attaining this improvement were similar between the A, B, and C categories, when compared with D (see Table 3 ). By logistic regression analysis, age, sex, body mass index, and COTE did not show a significant association with achieving a minimum clinically important difference in each outcome.

\section{Discussion}

This study sheds new light on the referral of patients with COPD to PR programs and the beneficial effects that may be expected by these interventions. To the best of our knowledge, this is the first paper that evaluates the effects of PR according to the most recent grading of COPD into categories A to D. The results confirm the benefits of PR across all categories of COPD.

It has been widely demonstrated how intensive, multidisciplinary PR programs with a focus on aerobic, muscle strength, and breathing control exercises as well as selfmanagement education are important to produce positive effects on COPD. This PR program complied with these requisites. The overall improvements recorded in these groups were similar to those in other studies. ${ }^{33-35}$

The new grading of COPD takes into account not only spirometric obstruction but also symptoms and exacerbations. Previous studies have assessed whether these variables predict greater benefit from PR programs. Success in exercise tolerance has been reported by Evans et al ${ }^{12}$ in $58 \%$ of the subjects as well as by Garrod et al ${ }^{13}$ with similar results in subjects with different degrees of dyspnea in the MRC scale. Man et $\mathrm{al}^{14}$ also found that subjects with mMRC scores of 1 and 2 improved their exercise performance and health status as much as subjects with higher mMRC scores. Although it has been accepted that patients with moderate COPD may benefit from PR programs, there is scarce evidence of the success of $P R$ in mild COPD. However, in a review by Jacome et al, ${ }^{16} 2$ retrospective studies and one randomized study have shown that subjects with mild COPD improved 6MWD, quality of life scores, and symptoms with PR. Berry et al ${ }^{17}$ also found that subjects in spirometric stages I, II, and III all had similar improvements in exercise tolerance outcomes and Chronic Respiratory Disease Questionnaire domains of dyspnea and fatigue after PR programs. 

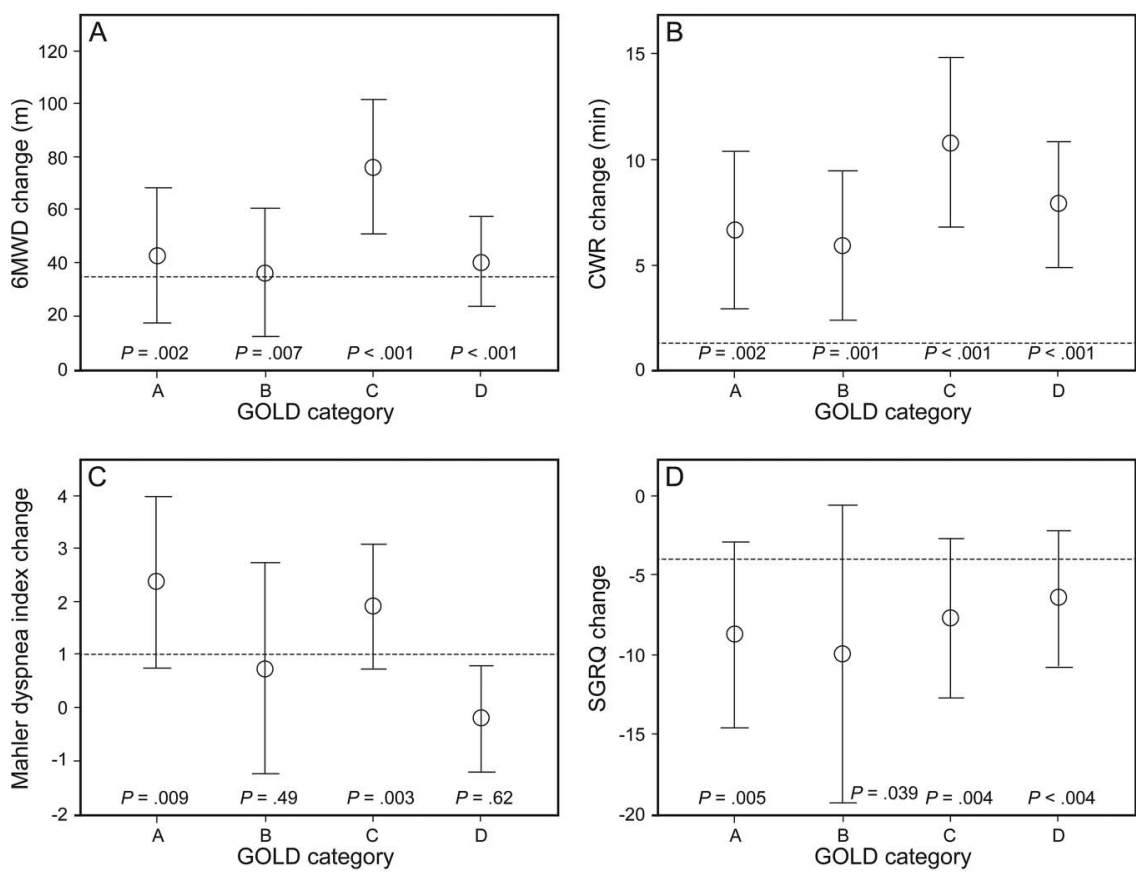

Fig. 1. Mean improvement of outcomes after pulmonary rehabilitation in the different Global Initiative for Chronic Obstructive Lung Disease (GOLD) categories. A: Change in 6-min walking distance (6MWD). B: Change in constant work rate (CWR). C: Change in dyspnea measured by Mahler's baseline and transitional dyspnea index. D: Change in St George Respiratory Questionnaire (SGRQ). Error bars express the means (circles) of outcome differences between the end and the beginning of the intervention (change) and corresponding $95 \% \mathrm{Cl}$. Dotted lines indicate the minimum clinically important difference improvement for each outcome (see text).

Table 3. Odds Ratios for Attaining Minimum Clinically Important Difference in Outcomes by Logistic Regression Models

\begin{tabular}{lccc}
\hline \hline Outcomes & Odds Ratio Estimate & $95 \%$ CI & $P$ \\
\hline 6MWD, m & & & \\
COPD A & 1.60 & $0.61-4.18$ & .34 \\
COPD B & 1.00 & $0.33-3.07$ & $>.99$ \\
COPD C & 1.71 & $0.73-4.03$ & .22 \\
CWR, min & & & \\
COPD A & 1.06 & $0.37-3.03$ & .92 \\
COPD B & 1.69 & $0.47-6.14$ & .43 \\
COPD C & 2.20 & $0.86-5.65$ & .10 \\
BDI/TDI & & & \\
COPD A & 2.73 & $0.99-7.54$ & .052 \\
COPD B & 1.13 & $0.35-3.60$ & .84 \\
COPD C & 2.02 & $0.84-4.87$ & .12 \\
SGRQ & & & \\
COPD A & 1.22 & $0.42-3.59$ & .71 \\
COPD B & 1.14 & $0.28-4.58$ & .85 \\
COPD C & 1.30 & $0.49-3.45$ & .59 \\
& & & \\
\hline 6MWD $=$ 6-min walk distance & & & \\
CWR = constant work rate \\
BDI/TDI = baseline and transitional dyspnea index & & \\
SGRQ = St George Respiratory Questionnaire & & \\
& & & \\
\hline
\end{tabular}

In the present study, subjects were graded into the 4 COPD categories by the mMRC (categories A and $\mathrm{C}$ had an $\mathrm{mMRC}$ score $\leq 1$ ), air-flow limitation, and number of exacerbations, and we also found that all benefitted from the PR program. Four main outcomes were used to assess PR program success in this study. The exercise performance outcomes (6MWD and constant work rate) have been validated as sensitive outcomes for PR programs, ${ }^{36}$ and Mahler's baseline and transitional dyspnea index has been shown to be a sensitive tool to detect moderate changes in dyspnea ${ }^{36,37}$ and assess the impact of dyspnea on activities of daily living. Although the St George Respiratory Questionnaire is a subjective measure of PR success, in previous studies ${ }^{15}$ it was shown that improvement in this score was more common than in objective measures such as 6MWD. This is of great importance because one of the primary goals of PR is to relieve symptoms and enhance tolerance to daily activities. $^{7}$

Regarding the change in functional capacity, the present study showed that subjects in categories $\mathrm{A}$ and $\mathrm{C}$ had greater improvement in 6MWD, when compared with category D. These results might be due to lower levels of baseline dyspnea in these categories compared with categories B and D. On the other hand, constant work rate, which markedly improved in all categories, was found to have similar variations in all of them, probably due to the nature of this test, which is measured according to each subject's personal best ( $80 \%$ of peak work rate).

Regarding the impact of symptoms on daily activities, we found differences between groups, with categories A 
and $\mathrm{C}$ having achieved greater improvements in baseline and transitional dyspnea index. We assume that these patients are less symptomatic and therefore usually less limited in their activities. This may also explain our findings in the 6MWD. The St George Respiratory Questionnaire was another very sensitive outcome for the PR program in all categories, with categories $\mathrm{A}, \mathrm{B}$, and $\mathrm{C}$ having shown a more pronounced effect.

This study highlights that despite the amplitude of the outcomes with a PR program, the odds of achieving a minimum clinically important difference are similar across all COPD categories. This finding is of the utmost relevance, since it reflects the real purpose of PR program referral.

Furthermore, all COPD categories, including the less severe patients, have been shown to benefit from PR programs and should be considered for these interventions. In our study, category A subjects represent a subset of patients who had been referred for hospital-based PR due to at least one of various motives that are not ubiquitous to all patients in this category (hypoxemic respiratory failure or desaturation on exertion, persistent productive cough, obesity or malnutrition, and also one case of hypercapnic respiratory failure). These complicating factors were found in an unexpectedly high proportion of subjects in this category. Mean $\mathrm{FEV}_{1}$ in this group was $65 \%$ but varied from 50 to $97 \%$. This also reflects the clinical heterogeneity of patients in COPD category A. Although some out-patientbased studies did not find consistent improvements in quality-of-life dimensions in less symptomatic individuals, ${ }^{38}$ the current study took place in a hospital setting where these subjects had the above complicating factors, thus having more scope for improvement, and where adherence rates are probably higher than in community settings.

We also found that category A subjects in this study did not differ significantly from those in other categories with regard to prevalence of comorbidities. Cardiovascular diseases were highly prevalent in all subjects, and no significant differences were found between categories. ${ }^{39,40}$ This illustrates that this subset of COPD category A individuals had more comorbidities than expected and thus were more prone to be selected for a PR program.

Previous data have suggested that COPD categories may not be sufficient to predict prognosis, disease progression, or mortality, and this may be due in part to the need to take into consideration other risk factors. ${ }^{41,42} \mathrm{We}$ may argue that comorbidities may further enhance the need for a PR program in COPD and do not impair its potential benefits. 43,44

This study has some limitations that should be addressed. This was not a randomized or controlled study, so patient inclusion bias could not be prevented. Nevertheless, the study reflects a real-world hospital-based out-patient PR program, and all of the individuals referred to the PR program entered the study, with no other selection bias. This study assessed the short-term impact of the PR program in different COPD categories. Further studies should be designed to search for long-term benefits of PR programs in each GOLD COPD category, such as the longterm impact in frequency and severity of exacerbations or in health-care use, as well as the adherence to lifestyle changes and home-exercise routine. It would also be interesting to find out whether PR programs may result in COPD category shifts and whether these shifts are shortor long-term.

Finally, depression and anxiety were not considered as outcomes in this study. However, subjects were systematically assessed with depression and anxiety scales and received psychological counseling if needed. Studies have shown that these interventions are important in the overall success of PR programs, ${ }^{45,46}$ and further studies could assess their relationship in different COPD categories and how they may influence other health status and symptom outcomes.

\section{Conclusions}

Overall, this study further contributes to show how COPD categories on their own may not be sufficient to predict which patients might benefit most from PR programs. Individuals in all COPD categories may benefit from PR achieving both statistically and clinically meaningful improvements in exercise performance and health-related quality of life. Multidisciplinary PR should be adopted as an integral part of management of patients with COPD, early in the course of the disease, and should not exclude apparently less severe or less symptomatic subjects. An individualized approach to COPD is important to identify characteristics and contributing factors, such as symptoms, comorbidities, or limitations to activities of daily living, that increase the burden of the disease and cause further impairment of quality of life but might be improved with interventions such as PR.

\section{REFERENCES}

1. GOLD. Global Initiative for Chronic Obstructive Lung Disease. Global strategy for the diagnosis, management, and prevention of chronic obstructive pulmonary disease. Updated 2015. Available from: http://www.goldcopd.org.

2. Spruit MA, Singh SJ, Garvey C, ZuWallack R, Nici L, Rochester C, et al. An official American Thoracic Society/European Respiratory Society statement: key concepts and advances in pulmonary rehabilitation. Am J Respir Crit Care Med 2013;188(8):e13-e64.

3. Decramer M, Gosselink R, Troosters T, Verschueren M, Evers G. Muscle weakness is related to utilization of health care resources in COPD patients. Eur Respir J 1997;10(2):417-423.

4. Swallow EB, Reyes D, Hopkinson NS, Man WD, Porcher R, Cetti EJ, et al. Quadriceps strength predicts mortality in patients with moderate to severe chronic obstructive pulmonary disease. Thorax 2007;62(2):115-120. 


\section{Pulmonary Rehabilitation in COPD According to GOLD CATEgories}

5. Gale NS, Duckers JM, Enright S, Cockcroft JR, Shale DJ, Bolton CE. Does pulmonary rehabilitation address cardiovascular risk factors in patients with COPD? BMC Pulm Med 2011;11:20.

6. GOLD. Global Initiative for Chronic Obstructive Lung Disease. Global strategy for diagnosis, management, and prevention of chronic obstructive pulmonary disease. Updated 2008. Available from: http://www.goldcopd.org.

7. McCarthy B, Casey D, Devane D, Murphy K, Murphy E, Lacasse Y. Pulmonary rehabilitation for chronic obstructive pulmonary disease. Cochrane Database Syst Rev 2015;(2):CD003793.

8. Lacasse Y, Wong E, Guyatt GH, King D, Cook DJ, Goldstein RS. Meta-analysis of respiratory rehabilitation in chronic obstructive pulmonary disease. Lancet 1996;348(9035):1115-1119.

9. Salman GF, Mosier MC, Beasley BW, Calkins DR. Rehabilitation for patients with chronic obstructive pulmonary disease: meta-analysis of randomized controlled trials. J Gen Intern Med 2003;18(3): 213-221.

10. Hoogendoorn M, van Wetering CR, Schols AM, Rutten-van Mölken MP. Is INTERdisciplinary COMmunity-based COPD management (INTERCOM) cost-effective? Eur Respir J 2010;35(1):79-87.

11. Bolton CE, Blakey JD, Morgan MD. The British Thoracic Society guideline on pulmonary rehabilitation in adults: your opinion is noted. Thorax 2014;69(4):388-389.

12. Evans RA, Singh SJ, Collier R, Williams JE, Morgan MD. Pulmonary rehabilitation is successful for COPD irrespective of MRC dyspnoea grade. Respir Med 2009;103(7):1070-1075.

13. Garrod R, Marshall J, Barley E, Jones PW. Predictors of success and failure in pulmonary rehabilitation. Eur Respir J 2006;27(4):788794.

14. Man WD, Grant A, Hogg L, Moore J, Barker RD, Moxham J. Pulmonary rehabilitation in patients with MRC Dyspnoea Scale 2. Tho$\operatorname{rax} 2011 ; 66(3): 263$.

15. Scott AS, Baltzan MA, Fox J, Wolkove N. Success in pulmonary rehabilitation in patients with chronic obstructive pulmonary disease. Can Respir J 2010;17(5):219-223.

16. Jácome C, Marques A. Pulmonary rehabilitation for mild COPD: a systematic review. Respir Care 2014;59(4):588-594.

17. Berry MJ, Rejeski WJ, Adair NE, Zaccaro D. Exercise rehabilitation and chronic obstructive pulmonary disease stage. Am J Respir Crit Care Med 1999;160(4):1248-1253.

18. McGavin CR, Gupta SP, McHardy GJ. Twelve-minute walking test for assessing disability in chronic bronchitis. Br Med J 1976;1(6013): 822-823.

19. Curtis JR, Deyo RA, Hudson LD. Pulmonary rehabilitation in chronic respiratory insufficiency. 7. Health-related quality of life among patients with chronic obstructive pulmonary disease. Thorax 1994; 49(2):162-170.

20. Fletcher CM, Elmes PC, Fairbairn AS, Wood CH. The significance of respiratory symptoms and the diagnosis of chronic bronchitis in a working population. Br Med J 1959;2(5147):257-266.

21. Bestall JC, Paul EA, Garrod R, Garnham R, Jones PW, Wedzicha JA. Usefulness of the Medical Research Council (MRC) dyspnoea scale as a measure of disability in patients with chronic obstructive pulmonary disease. Thorax 1999;54(7):581-586.

22. Celli BR, Cote CG, Marin JM, Casanova C, Montes de Oca M, Mendez RA, et al. The body-mass index, airflow obstruction, dyspnea, and exercise capacity index in chronic obstructive pulmonary disease. N Engl J Med 2004;350(10):1005-1012.

23. Divo M, Cote C, de Torres JP, Casanova C, Marin JM, Pinto-Plata $\mathrm{V}$, et al. Comorbidities and risk of mortality in patients with chronic obstructive pulmonary disease. Am J Respir Crit Care Med 2012; 186(2):155-161.
24. ATS Committee on Proficiency Standards for Clinical Pulmonary Function Laboratories. ATS statement: guidelines for the six-minute walk test. Am J Respir Crit Care Med 2002;166(1):111-117.

25. Vivodtzev I, Gagnon P, Pepin V, Saey D, Laviolette L, Brouillard C, Maltais F. Physiological correlates of endurance time variability during constant-workrate cycling exercise in patients with COPD. PLoS One 2011;6(2):e17007.

26. Borel B, Provencher S, Saey D, Maltais F. Responsiveness of various exercise-testing protocols to therapeutic interventions in COPD. Pulm Med 2013;2013:410748.

27. Holland AE, Nici L. The return of the minimum clinically important difference for 6-minute-walk distance in chronic obstructive pulmonary disease. Am J Respir Crit Care Med 2013;187(4):335-336.

28. Puhan MA, Mador MJ, Held U, Goldstein R, Guyatt GH, Schünemann HJ. Interpretation of treatment changes in 6-minute walk distance in patients with COPD. Eur Respir J 2008;32(3):637643.

29. Puente-Maestu L, Villar F, de Miguel J, Stringer WW, Sanz P, Sanz ML, et al. Clinical relevance of constant power exercise duration changes in COPD. Eur Respir J 2009;34(2):340-345.

30. Mahler DA, Weinberg DH, Wells CK, Feinstein AR. The measurement of dyspnea: contents, interobserver agreement, and physiologic correlates of two new clinical indexes. Chest 1984;85(6): 751-758.

31. Jones PW. Interpreting thresholds for a clinically significant change in health status in asthma and COPD. Eur Respir J 2002;19(3):398404.

32. Ringbaek T, Martinez G, Lange P. A comparison of the assessment of quality of life with CAT, CCQ, and St George Respiratory Questionnaire in COPD patients participating in pulmonary rehabilitation COPD 2012;9(1):12-15.

33. Barakat S, Michele G, George P, Nicole V, Guy A. Outpatient pulmonary rehabilitation in patients with chronic obstructive pulmonary disease. Int J Chron Obstruct Pulmon Dis 2008;3(1):155162.

34. van Wetering CR, Hoogendoorn M, Mol SJ, Rutten-van Mölken MP, Schols AM. Short- and long-term efficacy of a community-based COPD management programme in less advanced COPD: a randomised controlled trial. Thorax 2010;65(1):7-13.

35. Griffiths TL, Burr ML, Campbell IA, Lewis-Jenkins V, Mullins J, Shiels K, et al. Results at 1 year of outpatient multidisciplinary pulmonary rehabilitation: a randomised controlled trial. Lancet 2000; 355(9201):362-368.

36. de Torres JP, Pinto-Plata V, Ingenito E, Bagley P, Gray A, Berger R, Celli B. Power of outcome measurements to detect clinically significant changes in pulmonary rehabilitation of patients with COPD. Chest 2002;121(4):1092-1098.

37. Jones P, Lareau S, Mahler DA. Measuring the effects of COPD on the patient. Respir Med 2005;99(Suppl B):S11-S18.

38. Román M, Larraz C, Gómez A, Ripoll J, Mir I, Miranda EZ, et al. Efficacy of pulmonary rehabilitation in patients with moderate chronic obstructive pulmonary disease: a randomized controlled trial. BMC Fam Pract 2013;14:21.

39. Agusti A, Edwards LD, Celli B, Macnee W, Calverley PM, Müllerova $\mathrm{H}$, et al. Characteristics, stability and outcomes of the 2011 GOLD COPD groups in the ECLIPSE cohort. Eur Respir J 2013; 42(3):636-646.

40. Boland MR, Tsiachristas A, Kruis AL, Chavannes NH, Rutten-van Mölken MP. Are GOLD ABCD groups better associated with health status and costs than GOLD 1234 grades? A cross-sectional study. Prim Care Respir J 2014;23(1):30-37.

41. Soriano JB, Alfageme I, Almagro P, Casanova C, Esteban C, SolerCataluña JJ, et al. Distribution and prognostic validity of the new 


\section{Pulmonary Rehabilitation in COPD According to GOLD CATEgories}

Global Initiative for Chronic Obstructive Lung Disease grading classification. Chest 2013;143(3):694-702.

42. Soriano JB, Rodríguez MR. A golden goal in 2010, and another GOLD in 2014 in primary care, or vice versa. Prim Care Respir J 2014;23(1):5-6.

43. Franssen FM, Rochester CL. Comorbidities in patients with COPD and pulmonary rehabilitation: do they matter? Eur Respir Rev 2014; 23(131):131-141

44. Carreiro A, Santos J, Rodrigues F. Impact of comorbidities in pulmonary rehabilitation outcomes in patients with chronic ob- structive pulmonary disease. Rev Port Pneumol 2013;19(3): 106-113.

45. Paz-Díaz H, Montes de Oca M, López JM, Celli BR. Pulmonary rehabilitation improves depression, anxiety, dyspnea and health status in patients with COPD. Am J Phys Med Rehabil 2007; 86(1):30-36.

46. de Godoy DV, de Godoy RF. A randomized controlled trial of the effect of psychotherapy on anxiety and depression in chronic obstructive pulmonary disease. Arch Phys Med Rehabil 2003;84(8): $1154-1157$. 